\title{
Horizontal gaze palsy with progressive scoliosis
}

INSERM

\section{Source}

INSERM. (1999). Orphanet: an online rare disease and orphan drug data base. Horizontal gaze palsy with progressive scoliosis. ORPHA:2744

Horizontal gaze palsy with progressive scoliosis (HGPPS) is a rare congenital autosomal recessive disease, presenting in children and adolescents, and characterized by progressive scoliosis along with the absence of conjug ate horizontal eye movements and associated with failure of the somatosensory and corticospinal neuronal tracts to decussate in the medulla. 